\title{
A new compartmentalised rhizotron system for root phenotyping
}

\author{
Riccardo Sartoni, Walter Zegada-Lizarazu, Andrea Monti \\ Department of Agricultural Sciences, University of Bologna, Italy
}

\begin{abstract}
Although roots are the key organs for plant fitness, studies on root phenotyping and dynamics of water uptake are difficult and costly. Here we present a new compartmentalised rhizotron system that attempts to integrate some positive features of conventional methods for assessing root patterns at field and laboratory scale. The system has a petrolatum/paraffin hydrophobic film, which allows the compartmentalisation of soil layers along the cylinder profile, thus roots and soil moisture content are split into completely independent segments. In this preliminary study, we tested the system by creating a top-bottom split root arrangement that mimic the fluctuating levels of a water table to determine the dynamic interrelationship of canopy water conservation and root water acquisition from both shallow and deep roots of giant reed. Thanks to its versatility, the system enabled us to perform a root phenotyping study within distinct and independent soil portions.
\end{abstract}

\section{Introduction}

Despite edaphic stresses constitute the main limitation to plant growth (Lynch, 2007), roots traits have been poorly investigated com-

Correspondence: Andrea Monti, Department of Agricultural Sciences, University of Bologna, viale G. Fanin 44, 40127 Bologna, Italy.

E-mail: a.monti@unibo.it

Key words: Arundo donax; biomass; drought; giant reed; root; root length density; water use.

Acknowledgements: this work was supported by the EU under the $7^{\text {th }}$ Framework Program for Research (FP7-311929, WATBI0).

Conference presentation: SIA XLIII Congress, Pisa, 2014.

Received for publication: 22 December 2014.

Revision received: 24 March 2015.

Accepted for publication: 28 March 2015.

CC Copyright R. Sartoni et al., 2015

Licensee PAGEPress, Italy

Italian Journal of Agronomy 2015; 10:645

doi:10.4081/ija.2015.645

This article is distributed under the terms of the Creative Commons Attribution Noncommercial License (by-nc 3.0) which permits any noncommercial use, distribution, and reproduction in any medium, provided the original author(s) and source are credited. pared to the aboveground parts of the plant (Smith et al., 2000). In fact, though recent technological advancements favoured the study of roots, such studies remain elusive, costly, time-consuming and technically demanding, especially under field conditions where many uncontrolled factors intervene (Gregory, 2006).

Traditional approaches, like excavation and related trenching or soil coring methods, represent the most common approaches for exploring root architecture, distribution, and morphology under field conditions, however they are inadequate for addressing studies on root functioning. These methodologies shows several limitations: intensive destructive labour required during excavation, fine roots losses due of the need to adopt sample processing able to sift through large amounts of soil in a shorter time, the commonly cost effective restriction to uppermost soil layers and the large number of samples required, etc. (Bengough et al., 2000; Polomski and Kuhn, 2002; Fang et al., 2012).

Alternatively, non-destructive visual methods comprise different typologies of rhizotrons and windowed root containers, or small transparent boxes at laboratory level for root phenotyping at early growth stages (Polomski and Kuhn, 2002; La Marié et al., 2014), and more recently the mini-rhizotron system combining transparent pipes with an optical capture systems and an image analysis software. The mini-rhizotrons can be used in field studies to follow the roots growth and their turnover; however, its analysis is limited to a small surface area (Fang et al., 2012; Eberbach et al., 2013; Maeght et al., 2013). Other methods of analysis such as X-ray computed tomography or magnetic resonance imaging, have been used successfully, however, the high cost and the know-how needed strongly limit their applicability (Fang et al., 2012).

In general, all the excavation and visual methods for root analysis present limitations and strengths, depending on the conditions where they are used. The information that they provide individually could be used in a complementary manner. For example, the segmentation of the whole root system without cutting or disturbing them could reveal the real contribution of new and/or old roots to the crop nutrient and water acquisition strategies, root turnover, resilience, and the ability of plant to counterbalance soil drying and drought stress of upper roots with an increased efficiency of water uptake by deeper roots.

Therefore, a system that could integrate some (or many) of the principal characteristics of such systems could constitute an important insight for in deep ecophysiological and ecohydrological root studies. In the present article we aim at presenting and discussing the potentialities of a new rhizotron system for root phenotyping studies that represents an attempt to integrate the principal characteristics of visual and excavation methods. Rooting pattern, its dynamics, and functioning could be integrally evaluated in this system. The functioning of the system was tested by creating a top-bottom split root system that somehow mimics the fluctuating levels of a shallow water table, while allowing to determine the dynamic interrelationship of canopy water conservation and root water acquisition from both shallow and deep roots. 


\section{Materials and methods}

\section{Water uptake and root monitoring system}

In order to monitor root growth over time and its water uptake strategies along the soil profile a system consisting of cylindrical transparent plexiglass columns (rhizotrons) of $1.0 \mathrm{~m}$ height and $0.30 \mathrm{~m}$ diameter was built. Independent soil compartments were created following Zegada-Lizarazu and Iijima $(2004,2005)$ who worked on a smaller and more rudimentary setup. The upper and deeper compartments, of equal size, were separated by a transversal waterproof layer composed by a mixture of petrolatum/paraffin (about $1 \mathrm{~cm}$ thick; ratio 97:3) that prevents water movement between compartments, while allowing normal root growth in depth as reported by Clark et al. (2000). A 5 mm-opening plastic mesh was also incorporated into the layer to increase the tensile strength. Such water proof membrane was laid over a sandy loam soil that was previously packed uniformly in the lower compartment to reach a bulk density of about $1.3 \mathrm{~g} \mathrm{~cm}^{-3}$. Before filling the upper section of cylinder with soil, a number of tests were carried out to make sure that water do not pass through to the other side of the petrolatum/paraffin film.

Two pre-calibrated soil moisture sensors $\left(\mathrm{ECH}_{2} \mathrm{O} \mathrm{EC}-5\right)$ coupled with data loggers $(E m 5 b)$ were placed in the centre of the upper and lower cylinder compartments for the continuous monitoring (hourly) of soil moisture. Four sub-surface irrigation drippers with self-regulating emitters $\left(2.3 \mathrm{~L} \mathrm{~h}^{-1}\right)$ were installed at about $3-4 \mathrm{~cm}$ below the soil surface in the upper compartment and below the hydrophobic layer in the lower compartment, respectively (Figure 1C and E). Importantly, each self-regulating emitter was completely independent in terms of water volume supply capacity and source of water. Therefore, irrigation can be connected to an independent water tank equipped with a water pump thus to supply different water sources (e.g., isotopically traced water) to each compartment, or add fertilisers independently. To make roots grow in dark, rhizotrons were enclosed in an aluminium structure covered by insulating polycarbonate sheets (Figure 1).

Root growth monitoring was performed by drawing visible roots on tracing papers enveloping the cylinder surface. Different colour tracings were used at each measurement. Thereafter, root drawings were scanned for determining surface root length density (surface RLD) by a specific image analysis tool (ImageJ; Rasband WS, US NIH, Bethesda, MD, USA). The functioning of the system, in terms of root growth monitoring and water uptake strategies, was validated through destructive root sampling by weighting total root biomass in each compartment.

\section{System test}

The whole system was placed in a greenhouse equipped with a remote control automated system for temperature (avg. $24.7 \pm 5.6^{\circ} \mathrm{C}$ ) and relative humidity (avg. $41.4 \pm 13.1 \%$ ) control. Moreover, an automated weather station [Agricontrol snc, Albenga (SV), Italy; MCX$\operatorname{MFCOAB}(2 \mathrm{~T})]$ was placed next to the system. Soil characteristics were: $1 \% 0$ of total $\mathrm{N}, 8$ and $86 \mathrm{mg} \mathrm{kg}^{-1}$ of assimilable and exchangeable $\mathrm{K}$, respectively. Organic matter was $1.3 \%$. Micro-propagated plants of a local ecotype of giant reed (Arundo donax L.) were transplanted on 16 Dec. 2013. Before water treatments, soil moisture was adjusted to field capacity $(23 \% v / v)$ every three-four days to allow normal plant growth. The experiment was arranged in a completely randomised design, with six replications for each treatment (upper soil drought and well watered deeper soil; upper and deeper soil well watered). The treatments started when roots had completely colonised the lower copartments (about 95 days after transplanting). During drought stress, soil

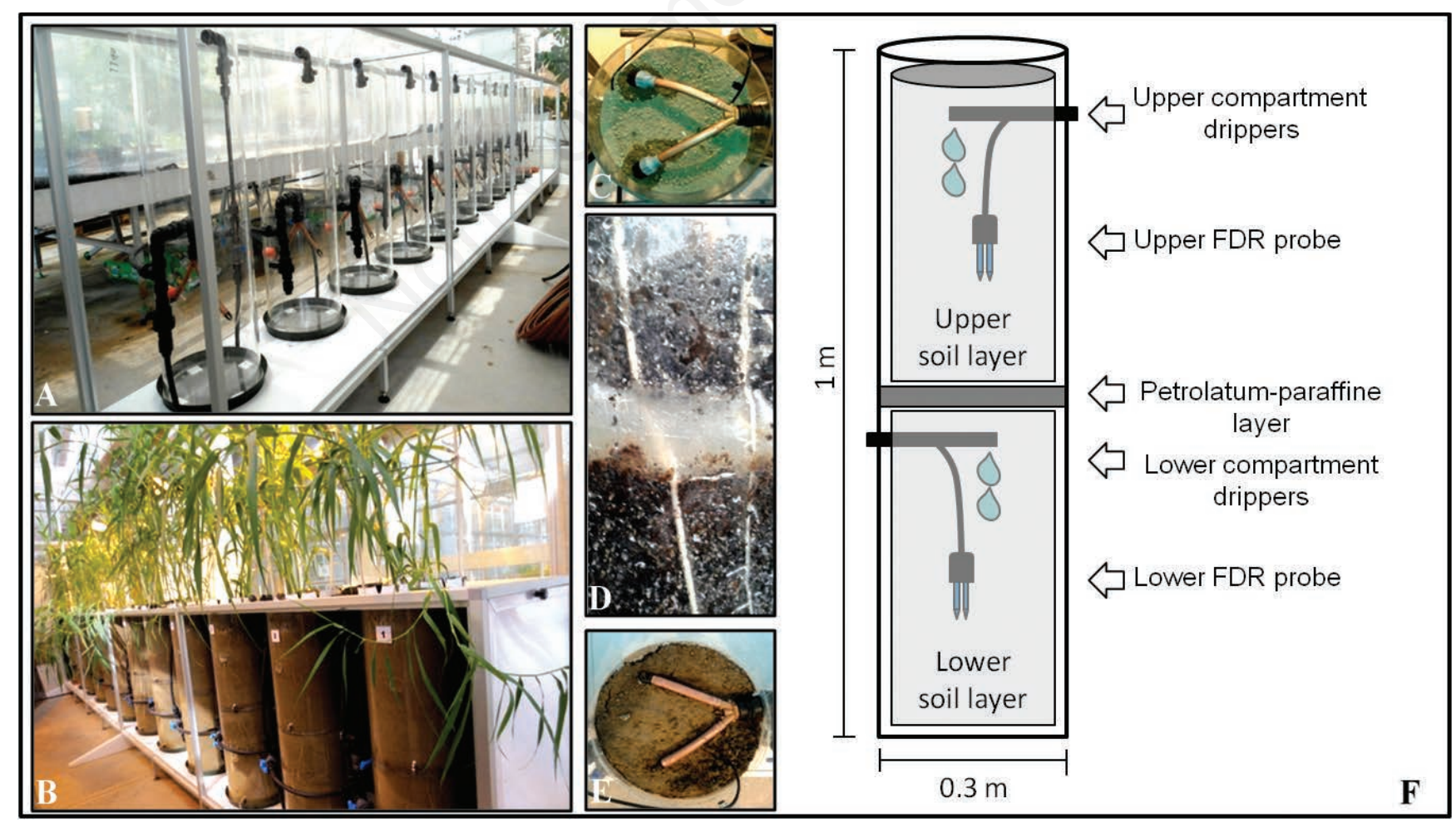

Figure 1. System set up: A) transparent cylinders (rhizotrons); B) system open for visual root determinations; C, E) sub irrigation (drippers); D) roots passing through the petrolatum/paraffin film; F) system outline. 
water was maintained close to $8 \% v / v$, while well-watered control to $23 \% v / v$. During the stress period soil moisture in either compartment was monitored and adjusted daily.

Rooting characteristics were determined every other week. Moreover, the root water uptake sources and efficiency patterns based on the root drawings and destructive samplings taken simultaneously at the end of the test trial were compared. Such validation was done in six randomly selected rhizotrons (three for each treatment) where roots of upper and lower compartments were carefully washed, collected and dried at $105^{\circ} \mathrm{C}$ to determine biomass accumulation. The washing phase, was conducted directly inside the cylinder, collecting the soil resulting from the washing on a slightly tilted plane along $5 \mathrm{~m}$ with, at the end, a sieve with holes about $1 \mathrm{~mm}$ of diameter in order to reduce the fine roots losses. Root water uptake efficiency (Zegada-Lizarazu et $a l ., 2012$ ) was expressed as the water used (frequency domain sensor probes) per unit of root length (in the case of the image analysis) or root weight (in the case of the final harvest).

\section{Statistical analysis}

The experiment was arranged in a completely randomised design, with six replicates and the differences between the means of all the parameters evaluated at each sampling date were tested using a oneway analysis of variance (ANOVA).

A Pearson's correlation coefficient was calculated to evaluate the relationship between the surface RLD and the root weight density (RWD).

\section{Results}

The effective water uptake partitioning sources from the upper and lower compartments by the rhizotron system is shown in Figure 2. In general, under the control conditions, water was mainly taken up from the topsoil layer rather than the bottom layer that, even though was kept close to field capacity, becomes a source only when the transpiration demand increases over the potential supply of the top layer. Whereas the drought stress imposed to the upper compartment forced giant reed to anticipate, and gradually increase, its water uptake from

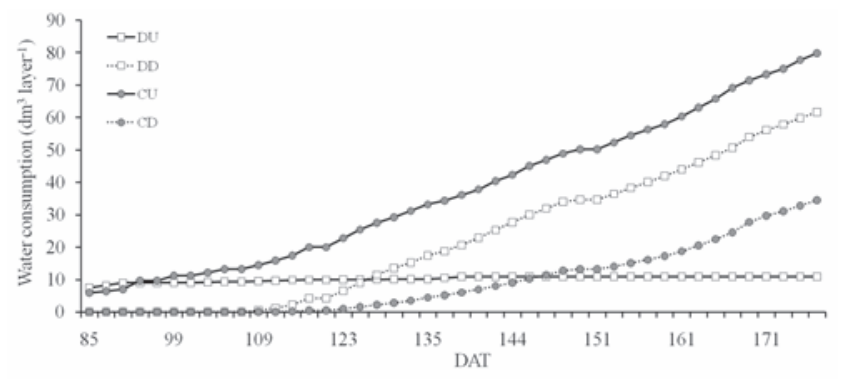

Figure 2. Cumulated water uptake in the upper and deeper soil layers with contrasting water regimes: control (well watered) at upper (CU) and deeper (CD) layers; drought stress at upper (DU) and deeper (DD) layers. the lower well watered layers (Figure 2). At the end of the experiment, the water taken up from the lower compartment in the drought treatment represented $85 \%$ of the total water absorbed, whereas in the control treatment about $70 \%$ of the total water used came from the upper compartment. At harvest time, the final water consumption of the control was $56 \%$ higher than in drought treatment. The transversal petrolatum/paraffin layer in each rhizotron allowed to maintain an averaged minimum water availability level of $9 \%$ and $19 \%$ before each irrigation cycle in the upper and lower compartments of the drought stress treatment and $17 \%$ in the upper compartment and $22 \%$ in lower one of control treatment. No evident mechanical impedance effects due to the presence of the waterproof layer were found on the behaviour of visible roots during the experiment.

Surface RLD was 3.3 times higher in control plants than drought treatment in the upper layers, while the deeper layers did not show statistically significant differences (Figure 3). Surface RLD determined from tracing visible roots on the external surface of the cylindrical rhizotrons, and real total root biomass were significantly correlated ( $r=0.71 \mathrm{P}=0.009$; Figure 4). The calculated root water uptake efficiency based on surface RLD and total biomass, in the upper and deeper compartments of each treatment, is presented in Figure 5. In the drought treatment, the water uptake efficiency increased significantly in the deeper compartment when the upper one progressively dried, reaching the values of the control's upper layer. Compared to the control, the root water uptake efficiency in the drought deeper layer increased by $+51 \%$ and $+53 \%$ respectively calculated on surface RLD and root biomass basis (Figure 5). The shallow roots in the drought upper layer show efficiency values not statistically different respect to the deep roots of the control treatment. In contrast to the drought treatment, that shows an equal trend between layers both on RLD and on RWD the basis, the control layers appear statistically different on RLD basis but equal on RWD.

\section{Discussion}

The compartmentalised rhizotron system (CRS) represents an attempt to integrate the advantages of the most common methods used for root phenotyping in open field (excavation, trenching and minirhi-

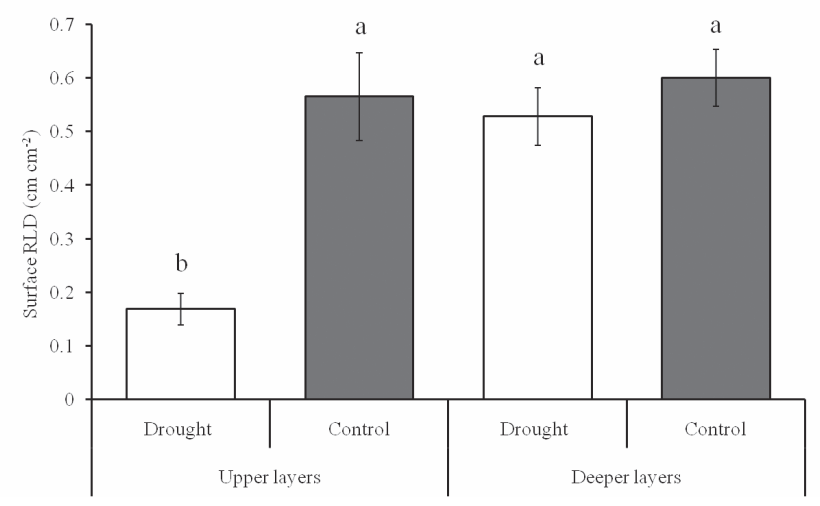

Figure 3. Surface root length density (surface RLD) estimated by root tracing papers. Vertical bars indicate the standard error of the mean. Different letters indicates a significant difference between treatments $(P \leq 0.05)$. 
zotrons) and greenhouse/laboratory (e.g., root-boxes). Pros and cons of CRS system against conventional methods have been summarised in Table 1. For example, the overall large variability of soil conditions in nature often neutralises treatment effects, unless a massive number of replications would be collected (Polomski and Kuhn, 2002; Fang et al., 2012). Therefore, the possibility of maintaining controlled conditions among rhizotrons, e.g., soil mixtures, soil water contents and regimes, temperatures, etc., dramatically reduces the experimental error and it allows distinguishing the treatment effects. Compared to field methods, CRS visibly reduces root losses and it is also less demanding in terms of labour and investments. With respect to subterranean chambers, in which several glass windows are installed on the soil walls, CRS requires less economic investments; it is dismountable, easily manageable, despite its relatively large dimensions, and more flexible in terms of experimental conditions. On the other hand, minirhizotrons based on transparent tubes inserted into the soil is a versatile technique for root distribution and turnover studies in the field (Poelman et al., 1996; Polomski and Kuhn, 2002; Majdi et al., 2005), however, the artificial conditions created for roots growth between the soil and the observation tubes during installation and the reduced spatial resolution (Johnson et al., 2001; Maeght et al., 2013) may result in under- or overestimations depending on soils structure, rooting habits, tube insertion angle, etc. (Eberbach et al., 2013). Since roots in our system grow inside the relatively large observation cylinders the pot size effect is potentially low. A confirmation has been obtained during the test trial by the calculation of the BVR (acronym of total plant dry biomass: rooting volume ratio) that for Arundo growth in the CRS system show the average value of $1.47 \mathrm{~g} \mathrm{~L}^{-1}$, below the limit threshold of $2 \mathrm{~g} \mathrm{~L}^{-1}$ recommended by Poorter et al. (2012) to prevent the pot influences. About the contact between cylinder walls and roots, it can be expected to affect the root behaviour in the same way of minirhizotron tubes, rhizoboxes and other roots container. Moreover, the fact that the present results of surface RLD (Figure 3 ) resulted in a significant relationship ( $\mathrm{r}=0.71 ; \mathrm{P}=0.009)$ with the total root biomass (Figure 4 ) allows to follow and compare the roots growth rate between treatments with a good degree of approximation. It should be also recognised that, even though in the present test-trial root drawing was used for RLD estimation, low demanding and automated HD-image acquisition methods could be adapted to this system for more rapid determinations.

An innovative aspect of the CRS system, compared to other lab splitroot system used for water uptake partitioning experiment (Faria et al., 2010), hormonal signalling in drought conditions (Saradadevi et al., 2014), or for testing the effects of salinity or soil pollutant (Flores et al.,
2002; Langer et al., 2010) is the possibility to create real horizontal layers, independent and variable in height along the soil profile, by positioning a transversal hydrophobic root-permeable film (Figure 1D) that allows to create different soil moisture/nutrient situations (e.g., a high water table, interchangeable drought soil layers, physical or chemical changes along the soil profile, irrigation with normal or deuterated water, etc.). Therefore, the system offers the possibility to isolate portions of the same root system and evaluate the functioning of specific root traits and segments during plant growth, e.g., deep vs shallow roots, allowing in-deep insights of the dynamic interrelationship of water acquisition in combination with hormonal signalling and/or labelling techniques and canopy water conservation strategies.

In this preliminary test-study we could distinguish the water uptake dynamics of upper and deeper roots of giant reed (Figure 2), while measuring the increase of water uptake efficiency by deeper roots as soil dried in the upper layer of the drought treatment (Figures 2 and 5). This highlights the plasticity of the giant reed root system, which without increasing the absorbing surface is able to modulate the water uptake efficiency in function of the soil water availability. Similar results were also reported by other authors using other approaches, however they could not reach such a level of detail and advanced

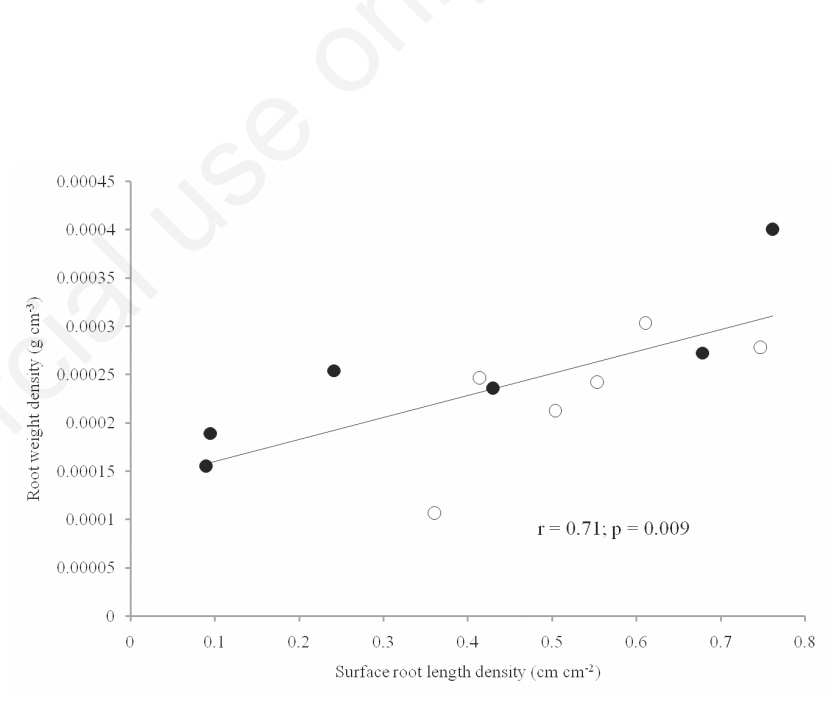

Figure 4. Correlation between surface root length density and root weight density. Full circle represent the values of the upper layers while the empty circle indicate the values of the deeper layers.

Table 1. Pros and cons of the compartmentalised rhizotron system compared to conventional field (e.g., excavation, trenching and minirhizotrons) and laboratory (e.g., root boxes) root analysis methods.

\begin{tabular}{|c|c|c|c|}
\hline \multicolumn{2}{|c|}{ CRS us field methods } & \multicolumn{2}{|c|}{ CRS vs lab methods } \\
\hline Pros & Cons & Pros & Cons \\
\hline $\begin{array}{l}\text { Controlled environment } \\
\quad \text { (e.g., water table depth); } \\
\text { Continuous monitoring; } \\
\text { High versatility; } \\
\text { Automated operations; } \\
\text { Low room demanding; } \\
\text { Independent soil/root layers; } \\
\text { Contained costs; } \\
\text { Seasonal and weather independent; } \\
\text { Low risks of pest and diseases }\end{array}$ & $\begin{array}{l}\text { Artificial conditions; } \\
\text { Confined volume; } \\
\text { Unfeasible radial root studies; } \\
\text { Sophisticated equipment, } \\
\text { facilities and skilled personnel }\end{array}$ & $\begin{array}{l}\text { High rooting volume; } \\
\text { Long experiment duration } \\
\text { thanks to the volume; } \\
\text { Setting different conditions } \\
\text { between deep and shallow } \\
\text { root system; } \\
\text { Space for many soil sensors; } \\
\text { 3D determination }\end{array}$ & $\begin{array}{l}\text { Room demanding; } \\
\text { Number of reps; } \\
\text { Less visible roots per inspection area; } \\
\text { Adaptability to alternative root } \\
\text { analysis technologies } \\
\text { (e.g., X-ray, tomography, etc.) }\end{array}$ \\
\hline
\end{tabular}


growth stages (Zegada and Iijima, 2004, 2005; Manschadi et al., 2010; Jongrungklang et al., 2012; Vadez et al., 2013). Field studies also confirmed that deep rooting habit of giant reed could be a major determinant of biomass productivity in semiarid conditions (Cosentino et al., 2014); again the authors could not distinguish the different root water uptake dynamics of defined layers and having specific soil moisture, as instead CRS allows. Finally, since water and nutrient uptake largely depends on root concentration and distribution along the soil profile, a limitation of CRS could be the adequate quantification of fine roots. However, with respect to the present case study the increasing uptake efficiency of giant reed at the deeper layer in the drought treatment was confirmed by the root water uptake efficiency based on the determination of total root biomass, which includes fine roots (Figure 5), thus validating the observed pattern on RLD. An improvement, able to minimise the differences between the water uptake efficiency calculated on RLD and on RWD observed in the control treatment, could be achieved equalising the number of the replicas subjected to quantification of the total root dry biomass (6) with that subjected to tracing (12).

\section{Conclusions}

A versatile system capable of reproducing a wide range of belowground environmental conditions has been developed for assessing rooting patterns and water uptake dynamics. The system allows the
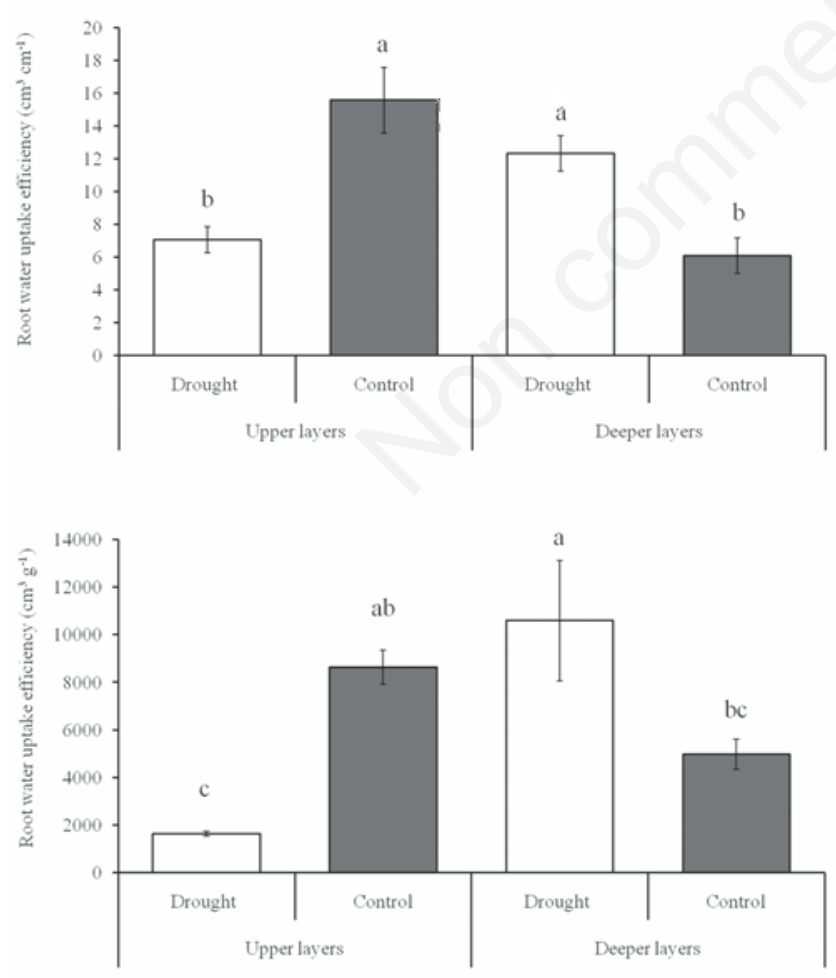

Figure 5. Root water uptake efficiency weighted on surface root length density (top) and total dry biomass (bottom). Vertical bars indicate the standard error of the mean. Different letters indicates a significant difference between treatments $(P \leq 0.05)$. non-destructive monitoring of the root system development and functioning. The system is capable of hosting plants of different rooting habits and until an advanced growth stage. A prerogative of this system is a hydrophobic film permeable to roots, which allows the segmentation of the root system within defined and independent soil compartments. The system is simple, easily implementable, modular and adaptable to different types of image acquisition techniques. An initial test with giant reed showed the versatility and effectiveness of the system for root phenotyping studies.

\section{References}

Bengough AG, Castrignano A, Pagès L, van Noordwijk M, 2000. Sampling strategies, scaling and statistics. In: Smith AL, Bengough AG, Engels C, van Noordwijk M, Pellerin S, van de Geijn SC (eds.), Root methods: a handbook. XIV. Springer, Berlin, Germany, pp 147-173.

Clark LJ, Aphale SL, Barraclough PB, 2000. Screening the ability of rice roots to overcome the mechanical impedance of wax layers: importance of test conditions and measurement criteria. Plant Soil 219:187-96.

Cosentino SL, Scordia D, Sanzone E, Testa G, Copani V, 2014. Response of giant reed (Arundo donax L.) to nitrogen fertilization and soil water availability in semi-arid Mediterranean environment. Eur. J. Agron. 60:22-32.

Eberbach PL, Hoffmann J, Moroni SJ, Wade LJ Weston LA, 2013. Rhizolysimetry: facilities for the simultaneous study of root behavior and resource use by agricultural crop and pasture systems. Plant Methods 9:3.

Fang S, Clark R Liao H, 2012. 3D quantification of plant roots architecture in situ. In: Mancuso S (ed.), Measuring roots - an updated approach. Springer, Berlin, Germany, pp 135-148.

Faria LN, Da Rocha MG, De Jong Van Lier Q, Casaroli D, 2010. A splitpot experiment with sorghum to test water uptake partitioning model. Plant Soil 331:299-311.

Flores P, Botella MA, Martinez V, Cerda A, 2002. Response to salinity of tomato seedlings with a split-root system: nitrate uptake and reduction. J. Plant Nutr. 25:177-87.

Gregory PJ, 2006. Plant roots: growth, activity and interaction with soils. Blackwell Publishing Ltd., Oxford, UK.

Johnson MG, tingey DT, Phillips DL, Storm MJ, 2001. Advancing fine roots research with minirhizotrons. Environ. Exp. Bot. 45:465-95.

Jongrungklang N, Toomsan B, Vorasoot N, Jogloy S, Boote KJ, Hoogenboom G, Patanothai A, 2012. Classification of root distribution patterns and their contributions to yield in peneaut genotype under mid-season drought stress. Field Crops Res. 127:181-90.

La Marié C, Kirchgessner N, Marschall D, Walter A, Hound A, 2014. Rhizoslides: paper-based growth system for non-destructive, high throughput phenotyping of root development by means of image analysis. Plant Methods 10:13.

Langer I, Syaffruddin S, Steinkellner S, Puschenreiter M, Wenzel WW, 2010. Plant growth and root morphology of Phaseolus vulgaris L. grown in a split-root system is affected by heterogeneity of crude oil pollution and mycorrhizal colonization. Plant Soil 332:339-55.

Lynch JP, 2007. Rhizoeconomics: the roots of shoot growth limitations. HortSci. 42:1107-9.

Maeght JL, Rewald B, Pierret A, 2013. How to study deep roots - and why it matters. Front. Plant Sci. 4:299.

Majdi H, Pregitzer K, Morén AS, Nylund JE, Ågren GI, 2005. Measuring fine root turnover in forest ecosystems. Plant Soil 276:1-8.

Manschadi AM, Christopher JT, Hammer GL, deVoil P, 2010. Experimental and modeling studies of drought-adaptative root 
architectural traits in wheat (Triticum aestivum L.). Plant Biosyst. 144:458-62.

Poelman G, van de Koppel J, Brouwer G, 1996. A telescopic method for photographing within 8x8 cm minirhizotrons. Plant Soil 185:163-7.

Polomsky J, Kuhn N, 2002. Root research methods. In: Waisel Y, Eshel A, Kafkafi U (eds.), Plant roots: the hidden half. Marcel Dekker Inc., New York, USA, pp 295-322.

Poorter H, Bühler J, van Dusschoten D, Climent J, Postma JA, 2012. Pot size matters: a meta-analysis of the effects of rooting volume on plant growth. Funct. Plant Biol. 39:839-50.

Saradadevi R, Bramley H, Siddique KHM, Edwards E, Palta JA, 2014. Reprint of "Contrasting stomatal regulation and leaf ABA concentrations in wheat genotypes when split root system were exposed to terminal drought”. Field Crop Res. 165:5-14.

Smith AL, Bengough AG, Engels C, van Noordwijk M, Pellerin S, van de
Geijn SC, 2000. Root methods: a handbook. XIV. Springer, Berlin, Germany.

Vadez V, Rao JS, Bhatnagar-Mathur P, Sharma KK, 2013. DREB1A promotes root development in deep soil layers and increase water extraction under water stress in groundnut. Plant Biol. 15:45-52.

Zegada-Lizarazu W, Iijima M, 2004. Hydrogen stable isotope analysis of water acquisition ability of deep roots and hydraulic lift in sixteen food crop species. Plant. Prod. Sci. 7:427-34.

Zegada-Lizarazu W, Iijima M, 2005. Deep root water uptake ability and water use efficiency of Pearl Millet in comparison to other millet species. Plant. Prod. Sci. 8:454-60.

Zegada-Lizarazu W, Zatta A, Monti A, 2012. Water uptake efficiency and aboveand belowground biomass development of sweet sorghum and maize under different water regimes. Plant Soil 351:47-60. 